\title{
How long is long enough? Adopting a risk-based approach to inform drainage management in closure designs
}

\author{
E Smedley Mine Earth Pty Ltd, Australia \\ S Mackenzie Mine Earth Pty Ltd, Australia \\ S Gregory Mine Earth Pty Ltd, Australia
}

\begin{abstract}
Landform design at closure has evolved from ad hoc principles, such as generic batter/berm configurations and top surface geometry, to designing structures to manage specific design rainfall events. However, there is conjecture around the application of appropriate rainfall events to inform closure designs. Design rainfall events adopted for closure may range from less than one in 100-year annual exceedance probability (AEP) to probable maximum precipitation (PMP). Often, the design rainfall events are selected on an arbitrary basis or as specified by the regulators. In accordance with standard engineering practice, defensible design criteria should be prepared prior to developing closure designs for mining landforms.

Designing for extreme events (those in the order of PMP) can result in greater closure costs, increased disturbance footprint, constructability issues or a resultant increase in other post-closure risks to the environment. These negatives can outweigh the potential consequences that the design intends to manage. Although appropriate in some cases, there is a risk that extreme events such as PMP are adopted as the default design criteria.

The 2016 Australian Rainfall and Runoff (ARR) guidelines and the Australian National Committee on Large Dams (ANCOLD) guidelines advocate the use of risk-based design in the management of threats posed by surface water. This is consistent with best practice mine closure planning. This paper demonstrates how a risk-based approach to drainage management can inform defensible design criteria and resultant closure designs.
\end{abstract}

Keywords: landform design, drainage management, risk assessment

\section{Introduction}

Successful drainage management is a key determinant in the success of closure works. Enhanced stability outcomes and lower rates of erosion are typically observed on rehabilitated mining landforms where drainage is well managed. Conversely, ineffective drainage management can result in large-scale erosion, mobilisation of contaminants and inability to achieve agreed closure criteria (Figure 1).

Effective drainage management is critical for long-term performance of rehabilitated mining landforms, including waste rock dumps (WRDs), tailings storage facilities, haul road ramps, diversions and other features. The design of drainage management controls (any measure or asset used to manage the potential impacts from drainage at closure) is an important aspect of mine closure planning.

A recurring challenge in mine closure planning is to determine how long closure designs can reasonably be expected to persist. From the proponent's perspective, there is a drive to reduce costs associated with closure works and to relinquish closed projects in a timely manner. The regulatory and community expectation is that closure works will generally be completed to a high standard and will last into perpetuity. A key question for closure practitioners is how long drainage management controls, critical to maintain the integrity of rehabilitated landforms, can reasonably be expected to function. 
Design criteria define the requirements that need to be met for a closure design. They are explicit goals that closure works must address in order to meet the design intent. In the context of drainage management, design criteria can include requirements as to how well the drainage management control will perform (the performance requirement) and how long the drainage management control will function at the minimum standard (the service life).

Risk assessments are increasingly utilised to inform drainage and flood management. This paper will cover some of the concepts that should be considered when developing design criteria and will explore the use of risk assessments to inform the development of design criteria for drainage management controls at closure.

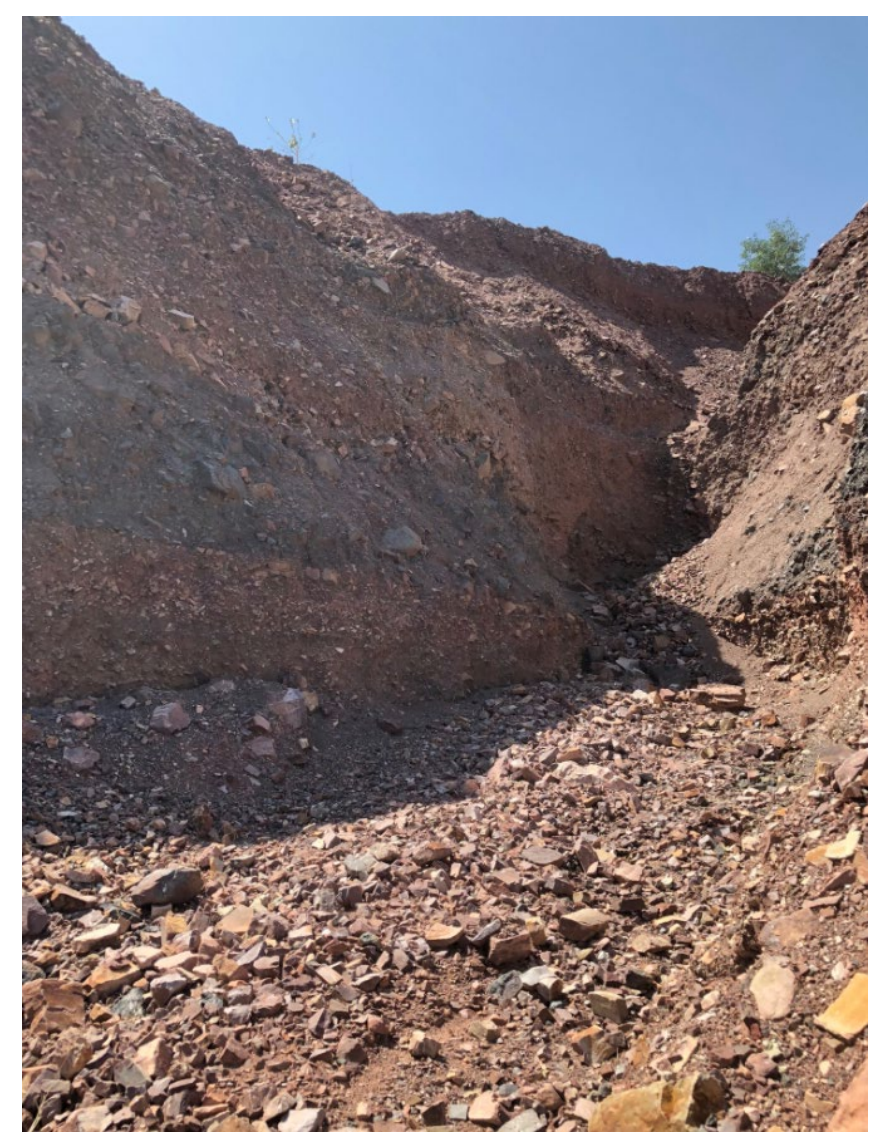

Figure 1 Waste rock dump erosion resulting from inadequate drainage controls

\section{$2 \quad$ Background}

As closure planning develops and becomes more sophisticated, the approach utilised to manage drainage within closure designs has advanced. Traditionally, ad hoc principles such as generic batter and berm configurations for landform slopes were utilised, whereas now it is more common to design drainage management controls to adequately perform under specific flood events. This has come about partially in response to recurring historical issues resulting from uncontrolled drainage and from stakeholders seeking greater certainty around closure designs.

Relevant guidance documents are ambiguous in relation to closure designs and tend to adopt terminology such as 'long-term' timescales (International Council on Mining and Metals [ICMM] 2019; Department of Mines and Petroleum [DMP] \& Environmental Protection Authority [EPA] 2015). In the absence of specific guidance, there is often arbitrary expectations regarding the design criteria to be applied to closure designs for mining landforms. Where considered (and it remains an issue that it frequently is not), adopted design criteria can range from one in 100-year annual exceedance probability (AEP) events to probable maximum precipitation (PMP) events, with little to no rationale. Little, if any, consideration is given to the service life 
requirements of the design. Such an arbitrary allocation of design criteria does not align with the risk-based approach to mine closure planning advocated in ICMM (2019) and DMP \& EPA (2015).

It is pertinent to adopt a risk-based approach to closure designs for mining landforms as there are often a multitude of variables to consider, including the location of the project, site-specific environmental values and threats, climatic conditions, nature of mine waste materials, adjacent topographic and regional drainage, scale of disturbance, stakeholder expectations and post-mining land use. Also, factors such as competing requirements for limited resources, such as durable rock armour, are common for closure projects and can impact the closure design for a mining landform. In this instance, such resources should be prioritised for higher risk areas.

A one-size-fits-all approach for developing design criteria for drainage management is not appropriate for mining landform closure designs. Adopting a site-specific risk-based approach, however, provides for robust, defensible and standardised development of design criteria.

A risk-based approach enables informed decisions to be made, to achieve the greatest reduction in risk and to establish design criteria to achieve an acceptable level of risk. Such an approach enables consideration of the additional impacts associated with adopting higher design criteria (such as increased disturbance footprint) compared to the relative benefits of the increased design requirements (such as decreased erosion). In some instances, the increased disturbance to manage the risk event may exceed the potential impact should the risk event be realised and therefore may result in a worse environmental outcome and greater cost.

The 4th edition of the Australian Rainfall and Runoff (ARR) guidelines were published in 2016. The ARR guideline informs flood management in Australia and incorporates a risk-based approach for drainage management that reflects contemporary management practices (Ball et al. 2016a).

\section{Service life and performance}

In considering the risks associated with drainage management and closure designs for mining landforms, it is necessary to consider both service life (how long the control will remain in service for) and performance (how effective the control will perform). Considerations for these aspects are presented below.

\subsection{Terminology}

A range of terms are routinely applied to describe the service life and performance of engineered drainage management controls for mining landforms, and this can result in confusion among stakeholders. Five common terms that are applied include design service life (DSL), effective service life (ESL), average recurrence interval (ARI), AEP and PMP.

\subsubsection{Design service life and effective service life}

The terms DSL and ESL both refer to the duration that the drainage management control is expected to function in accordance with the design intent.

The DSL is the total period that a drainage management control has been designed to work or perform its intended function within specified design parameters (e.g. performance-based design criterion) and operating conditions (McLuckie et al. 2016; Department of Transport and Main Roads 2015).

The ESL is the total period that a drainage management control provides its intended function before repair or replacement is required (McLuckie et al. 2016). The ESL is impacted by a range of site-specific factors that can either increase or decrease the ESL, as described in Section 3.2.

Consideration of the ESL is critical in evaluating risk and establishing appropriate design criteria for the closure of mining landforms. 


\subsubsection{Average recurrence interval and annual exceedance interval}

The ARI and the AEP are different terms that refer to the relative frequency of a given rainfall or flood event. A third term, exceedances per year (EY) is also used although typically only for very frequent rainfall events.

The ARI is defined as the average time period between occurrences equalling or exceeding a given value and was the main measure of the frequency of a rainfall event presented in previous editions of ARR. The ARI is typically referred to as an ' $X$ ' years event. The term ARI was criticised as it was regularly misinterpreted as implying that the associated event magnitude was only exceeded at regular intervals and that they are referring to the expected elapsed time until the next exceedance (for example a 100-year ARI may only occur once every 100 years) (Ball et al. 2016b).

The AEP is the probability of an event being equalled or exceeded within a year. It is typically referred to a percentage likelihood of occurrence in any given year (e.g. a 10\% AEP event has a $10 \%$ likelihood of occurrence at least once every year), although can also be referred to as a ' 1 in X' year event as detailed below (Ball et al. 2016b).

The standard method utilised to calculate the ARI and the AEP differs. The AEP considers only the largest event each year, whereas the ARI considers all events and could therefore incorporate two five years events in a single year, for example. This means that the values for the different methods are not equal; for example, a $10 \%$ AEP event does not equate to a 10 -year ARI event. For all but the most frequent events, the AEP method is the preferred method.

Ball et al. (2016b) developed a recommended terminology for referring to different scale rainfall events (Table 1). Very frequent events are typically referred as the EY. Frequent to rare events are typically referred to the AEP percentage. Rare to extreme events are typically referred to as the AEP ' 1 in X years'. Different studies utilise different conventions for rare and very rare events; studies considering the likelihood of regional flooding have typically considered the percentage likelihood on any given year. Studies considering the frequency of overtopping of dams have traditionally adopted the ' 1 in X years' terminology. Importantly the two terms are equivalent for AEP events. Bold figures within Table 1 refer to the preferred terminology for different events as defined by Ball et al. (2016b).

Table 1 ARR equivalent events and preferred terminology for event frequency (Bell et al. 2016b)

\begin{tabular}{llll}
\hline $\begin{array}{l}\text { Equivalent } \\
\text { year }\end{array}$ & $\begin{array}{l}\text { Annual } \\
\text { exceedance } \\
\text { probability (\%) }\end{array}$ & $\begin{array}{l}\text { Annual exceedance } \\
\text { probability } \\
(\mathbf{1} \text { in } \mathbf{\text { yrs} )}\end{array}$ & $\begin{array}{l}\text { Annual } \\
\text { recurrence } \\
\text { interval (yrs) }\end{array}$ \\
\hline $\mathbf{6}$ & 99.75 & 1.002 & 0.17 \\
$\mathbf{2}$ & 86.47 & 1.16 & 0.5 \\
$\mathbf{1}$ & $\mathbf{6 3 . 2 1}$ & 1.58 & 1 \\
$\mathbf{0 . 5}$ & $\mathbf{3 9 . 3 5}$ & 2.54 & 2 \\
$\mathbf{0 . 2}$ & $\mathbf{1 8 . 1 3}$ & 5.52 & 5 \\
0.11 & $\mathbf{1 0}$ & 10 & 9.49 \\
0.05 & $\mathbf{5}$ & 20 & 20 \\
0.01 & $\mathbf{1}$ & $\mathbf{1 0 0}$ & 100 \\
0.005 & $\mathbf{0 . 5}$ & $\mathbf{2 0 0}$ & 200 \\
0.001 & $\mathbf{0 . 1}$ & $\mathbf{1 , 0 0 0}$ & 1,000 \\
0.0005 & $\mathbf{0 . 0 5}$ & $\mathbf{2 , 0 0 0}$ & 2,000 \\
0.0002 & 0.02 & $\mathbf{5 , 0 0 0}$ & 5,000 \\
NA & NA & PMP & NA \\
\hline
\end{tabular}


Very rare and extreme events are determined based upon extrapolation of observed events. As such, there is much greater uncertainty in the prediction for more extreme events. PMP is defined as 'the greatest depth of precipitation for a given duration that is physically possible over a given size area at a particular geographical location at a certain time of year' (World Meteorological Organization 1986). In practice, PMP estimates are based on a set of simplifying assumptions and are only a best guess of maximised extrapolations from observed large events (Nathan \& Weinmann 2016).

\subsection{Estimating service life}

Estimating the ESL of drainage management controls required for the closure of mining landforms can be difficult. The potential ESL for a range of drainage management controls are presented in Table 2. The ESL is a function of design, construction materials, construction quality, environmental conditions, the maintenance regime and use (McLuckie et al. 2016). Even before accounting for potential degradation factors, the ESL of most drainage management controls are unlikely to meet the expectations of stakeholders, including regulatory bodies and post-mining land-users.

Table 2 Infrastructure types and potential ESL (from McLuckie et al. 2016)

\begin{tabular}{ll}
\hline Infrastructure type & Typical ESL \\
\hline Stormwater pipes & $80-100$ years \\
Roads & $35-110$ years \\
Open stormwater channel & $10-100$ years \\
Locks and weirs & $40-200$ years \\
Dams & $50-500$ years \\
\hline
\end{tabular}

Factors that may decrease the ESL of drainage management controls for mining landforms include:

- Often closure works are not undertaken by specialist contractors and are not constructed to an equivalent standard as civil works would be. Relatively small variances to design levels can greatly reduce the performance of drainage management controls (Smedley et al. 2016).

- Availability to the required construction materials is often limited and, given the remote location of most mine sites, cannot easily be sourced. The ESL can be dramatically reduced where available materials are not fit for purpose or where materials are prone to mechanical or chemical weathering.

- Performance of drainage management controls can be compromised by substrate material properties, which may be prone to differential consolidation, dissolution or piping.

- Large influxes of sediment from upstream sources and loss of capacity resulting from erosion of downstream batters and resultant degradation of crest bund height can also impact the ESL.

- Vegetation growth can consume storage capacity within water retention controls and root balls can impact upon the integrity of drainage management controls.

- Environmental conditions will vary by site. Typically, drainage management controls located within tropical environments will degrade at a faster rate than those in subtropical environments as they are exposed to more high-intensity rainfall on a regular basis. Exposure to rainfall events that exceed the design capacity of the drainage management control may compromise its long-term performance. Climate change may also alter the likelihood and occurrence of these events.

- Ecological processes-such as vegetation, insect and microbial activity-can impact upon geotechnical and drainage management parameters, meaning they do not function as intended (Fourie \& Tibbett 2007; DeJong et al. 2015). 
- Maintenance works post-closure are typically undertaken at a much lower frequency (if at all), especially after the initial post-closure monitoring and maintenance period and after machinery has been removed from the site.

To offset some of the impacts associated with these factors, consideration should be given to adopting more conservative designs with increased redundancy-such as allowance for sediment and vegetation accumulation; avoiding high-maintenance controls such as rock-lined drains, the use of diversion bunds and drop-structures where possible; increased quality control during construction; and an improved understanding of the long-term behaviour of materials and their weathering products.

The combination of unknowns and potential factors that may impact upon the ESL lends itself to a risk-based approach to develop a likely ESL as well as potentially upper and lower bounds for what the final ESL may be.

\subsection{Assessment of performance}

Compared to determining the ESL, predicting performance of drainage management controls is simpler. Performance is normally modelled around the capacity of the control to perform its designated function (e.g. storage, conveyance or retention) for a given design event. This is typically done using modelling tools such as TUFLOW, DRAINS or RORB models.

Regardless of the model utilised to assess performance, the modelling parameters should consider both the performance of the control in its 'as-constructed' state and likely conditions at the end of the ESL. Modelling different scenarios can assist in determining the ESL; for example, assessment of the capacity to retain both sediment and vegetation before a given event can no longer be retained can inform the refinement of the ESL.

\section{Risk-based approach}

A range of risk assessment methods can be applied to assess mine closure-related surface water risks. In the mine closure context, a range of potential impacts (including environmental, public safety and amenity, and financial implications) should be considered within the risk assessment. Given the range of potential impact types, a qualitative risk assessment approach is generally appropriate and reflects the approach presented below in Section 4.1. Using this approach, the acceptable level of risk and the consequences of a risk event can be used to calibrate the design criteria for drainage management controls at closure.

\subsection{Process}

A range of risk-based approaches can be adopted to determine appropriate design criteria for closure. The most basic of these is a qualitative risk assessment utilising a risk matrix to assess the risk for different events, and this process is presented below. Such a risk assessment is routinely undertaken as part of the mine closure planning process.

Mine closure-related surface water risk events should be identified for the project along with potential management options. An example of typical surface water risks for a constructed mining landform are presented in Table 3. 
Table 3 Example of surface water risk events in a mine closure context

\begin{tabular}{|c|c|c|}
\hline Risk event & Potential consequence & Management options \\
\hline \multirow{3}{*}{$\begin{array}{l}\text { Overtopping of } \\
\text { drainage management } \\
\text { controls on the WRD }\end{array}$} & \multirow{3}{*}{$\begin{array}{l}\text { Erosion on WRD batters, } \\
\text { loss of function of the } \\
\text { water retention structure }\end{array}$} & $\begin{array}{l}\text { Design water retention features to meet } \\
\text { appropriate design criteria. }\end{array}$ \\
\hline & & $\begin{array}{l}\text { Divert drainage away from the top surface } \\
\text { and berms through drains or spillways to } \\
\text { natural ground. }\end{array}$ \\
\hline & & $\begin{array}{l}\text { Utilise internal bunding on the WRD to } \\
\text { reduce the potential for concentration of } \\
\text { surface water. }\end{array}$ \\
\hline \multirow{2}{*}{$\begin{array}{l}\text { Upstream drainage } \\
\text { flowing around the } \\
\text { toe of the WRD }\end{array}$} & \multirow[t]{2}{*}{$\begin{array}{l}\text { Erosion at the toe of the } \\
\text { WRD }\end{array}$} & $\begin{array}{l}\text { Locate WRD outside of upstream drainage } \\
\text { lines where possible. }\end{array}$ \\
\hline & & $\begin{array}{l}\text { Rock armour the interface between natural } \\
\text { ground and the WRD where drainage } \\
\text { concentration is likely. }\end{array}$ \\
\hline \multirow[t]{3}{*}{$\begin{array}{l}\text { Failure of drainage } \\
\text { diversions }\end{array}$} & \multirow[t]{3}{*}{$\begin{array}{l}\text { Erosion, loss of function } \\
\text { of the drainage diversion }\end{array}$} & $\begin{array}{l}\text { Design and construct drainage diversions to } \\
\text { meet appropriate design criteria. }\end{array}$ \\
\hline & & $\begin{array}{l}\text { Where possible, limit the catchment area } \\
\text { reporting to the diversion. }\end{array}$ \\
\hline & & $\begin{array}{l}\text { Where possible, direct drainage over natural } \\
\text { ground. }\end{array}$ \\
\hline \multirow{4}{*}{$\begin{array}{l}\text { Batter erosion from } \\
\text { incidental rainfall }\end{array}$} & \multirow{4}{*}{$\begin{array}{l}\text { Erosion, sediment runoff, } \\
\text { loss of cover over } \\
\text { potentially acid forming } \\
\text { cells }\end{array}$} & Avoid steep and high batters. \\
\hline & & Apply durable rock to final WRD batters. \\
\hline & & Contour ripping on outer batters. \\
\hline & & Vegetation establishment. \\
\hline $\begin{array}{l}\text { Piping failure through } \\
\text { the WRD top surface } \\
\text { and berms }\end{array}$ & $\begin{array}{l}\text { Erosion, loss of function } \\
\text { of the water retention } \\
\text { structures }\end{array}$ & $\begin{array}{l}\text { Avoid standing water close to the WRD crest, } \\
\text { especially over fine-grained material. }\end{array}$ \\
\hline
\end{tabular}

In the closure context, the duration of the assessment period is indefinite. As a result, rather than focus on 'likelihood' as in typical risk assessments, frequency should be adopted as an appropriate alternative measure (Table 4). The consequence for each risk event should be determined; an example of typical consequence levels is presented in Table 5, where relevant other factors may also be considered. A risk matrix should be prepared for the project; a sample risk matrix is presented in Table 6.

Table 4 Definitions for frequency descriptors (Ball et al. 2016b) (continued next page)

\begin{tabular}{llll}
\hline Frequency descriptor & EY & AEP (\%) & AEP (1 in X years) \\
\hline Very frequent & 12 & & \\
& 6 & & \\
& 2 & 63.21 & \\
Frequent & 1 & 50 & \\
& 0.69 & 20 & \\
Rare & & 10
\end{tabular}




\begin{tabular}{|c|c|c|c|}
\hline Frequency descriptor & EY & AEP (\%) & AEP ( 1 in $X$ years) \\
\hline & & 5 & \\
\hline & & 2 & \\
\hline & & 1 & 100 year \\
\hline \multirow[t]{4}{*}{ Very rare } & & 0.5 & 200 years \\
\hline & & 0.2 & 500 years \\
\hline & & 0.1 & 1,000 years \\
\hline & & 0.05 & 2,000 years \\
\hline \multirow[t]{2}{*}{ Extreme } & & 0.02 & 5,000 years \\
\hline & & PMP & \\
\hline
\end{tabular}

Table 5 Typical consequence levels (adapted from Department of Environmental Regulation 2017)

\begin{tabular}{|c|c|c|}
\hline Consequence level & Environment & Public health and amenity \\
\hline Insignificant & $\begin{array}{l}\text { Minimal onsite impacts } \\
\text { Completion criteria not compromised }\end{array}$ & $\begin{array}{l}\text { Minimal impacts to local scale } \\
\text { amenity }\end{array}$ \\
\hline Minor & $\begin{array}{l}\text { Low-level onsite impacts } \\
\text { Minimal local scale offsite impacts } \\
\text { No detectable wider scale offsite } \\
\text { impacts } \\
\text { Completion criteria are likely to be met }\end{array}$ & $\begin{array}{l}\text { Low-level impact to local scale } \\
\text { amenity }\end{array}$ \\
\hline Moderate & $\begin{array}{l}\text { Mid-level onsite impacts } \\
\text { Low-level local scale offsite impacts } \\
\text { Minimal wider scale offsite impacts } \\
\text { Completion criteria are at risk of not } \\
\text { being met }\end{array}$ & $\begin{array}{l}\text { Low-level or occasional medical } \\
\text { treatment } \\
\text { Mid-level impact to local scale } \\
\text { amenity }\end{array}$ \\
\hline Major & $\begin{array}{l}\text { High-level onsite impacts } \\
\text { Mid-level local scale offsite impacts } \\
\text { Low-level wider scale offsite impacts } \\
\text { Completion criteria are not met } \\
\text { Short-term impact to an area of high } \\
\text { conservation value or special } \\
\text { significance }\end{array}$ & $\begin{array}{l}\text { Mid-level or frequent medical } \\
\text { treatment } \\
\text { High-level impact to local scale } \\
\text { amenity }\end{array}$ \\
\hline Catastrophic & $\begin{array}{l}\text { Catastrophic onsite impacts } \\
\text { High-level or greater local scale offsite } \\
\text { impacts } \\
\text { Mid-level or greater wider scale offsite } \\
\text { impacts } \\
\text { Mid to long-term or permanent impact } \\
\text { to an area of high conservation value or } \\
\text { special significance } \\
\text { Completion criteria will never be met }\end{array}$ & $\begin{array}{l}\text { Loss of life } \\
\text { High-level or ongoing medical } \\
\text { treatment } \\
\text { Permanent loss of local scale } \\
\text { amenity }\end{array}$ \\
\hline
\end{tabular}




\begin{tabular}{|c|c|c|c|c|c|c|}
\hline & & \multicolumn{5}{|c|}{ Consequence } \\
\hline & & Insignificant & Minor & Moderate & Major & Catastrophic \\
\hline \multirow{5}{*}{ 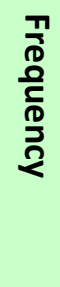 } & Very frequent & Low & Medium & High & Extreme & Extreme \\
\hline & Frequent & Low & Medium & High & High & Extreme \\
\hline & Rare & Very low & Low & Medium & High & High \\
\hline & Very rare & Very low & Very low & Low & Medium & High \\
\hline & Extreme & Very low & Very low & Low & Medium & High \\
\hline
\end{tabular}

\subsection{Developing design criteria}

The outcomes from the risk assessment can be used to develop appropriate design criteria and the ESL for drainage management controls.

In most cases, drainage management controls are likely to result in a reduction of the frequency of a risk event as opposed to the consequence of a risk event. If the consequence is taken as a given, then the required frequency to achieve an acceptable level of risk is known. For example, a risk event with a moderate consequence would require a very rare frequency to achieve a low residual risk. As such, the design criteria should be developed with an exceedance probability of between 1 in 200 years and 1 in 2,000 years (Table 4). For a water retention structure (such as a backsloping berm) and the typical ESL for a dam structure of between 50 and 500 years (Table 2), a very rare risk event frequency is likely to be achievable only if suitable construction materials are available onsite and sufficient redundancy is incorporated into the design to allow for the degradation of the drainage management controls. Appropriate design criteria for this scenario could be an ESL of 200 years, during which the system will be able to store the critical 1 in 1,000-year AEP event. Using the example of a backsloping berm, methods to assess the potential changes to the hypothetical berm associated with sediment accumulation and weathering of surface materials over the 200-year ESL are presented in Smedley et al. (2016).

Using the risk matrix in Table 6, to achieve an acceptable level of risk, extreme rainfall events would only be utilised to inform closure designs where the consequence of a risk event is catastrophic. This is consistent with the design standards applied within Australian National Committee on Large Dams (2012), where a PMP level design criterion is only required where the consequence of failure is catastrophic (or severe with the potential to impact upon a large population). Similarly, a $1 \%$ AEP design criterion is likely to be acceptable only where potential consequences are minor.

To continue to function in accordance with the design, all drainage controls, regardless of how simple or complex will require some level of monitoring and potentially maintenance. In the absence of regular maintenance, the ESL of many common drainage management controls are unlikely to function long enough to meet the design criteria if there are no maintenance plans in place to ensure the refurbishment or replacement of these controls. For example, using an open channel diversion to prevent large-scale erosion events is unlikely to operate in accordance with the performance-based design criteria for a long enough period to be an acceptable closure solution without ongoing repairs. Passive controls can often be engineered to incorporate a longer ESL and as they degrade over time are more likely to do so in a manner that the impacts can be assimilated into the environment. 


\section{Conclusion}

Risk-based approaches are increasingly common for use in drainage management, as reflected in the most recent revision of ARR. Adopting a risk-based approach provides a standardised and systematic method to develop design criteria for effective drainage management in mine closure planning. In this way, the design criteria can be aligned with stakeholder expectations, and where limited resources exist, they can be deployed in the most effective manner possible to reduce the risk of unacceptable post-closure impacts.

\section{References}

Australian National Congress on Large Dams 2012, Guidelines on Tailings Dams - Planning, Design, Construction, Operation and Closure, Australian National Congress on Large Dams, Hobart.

Ball, J, Babister, M, Nathan, R, Weeks, W, Retallick, M \& Testoni, I (eds) 2016a, Australian Rainfall and Runoff: A Guide to Flood Estimation, Commonwealth of Australia, Canberra.

Ball, J, Babister, M, Retallick, M, Ling, F \& Thyer, M 2016b 'Fundamental issues', Book 1, Australian Rainfall and Runoff - A Guide to Flood Estimation, Commonwealth of Australia, Canberra.

DeJong, J, Tibbett, M \& Fourie, AB 2015, 'Ecological systems that evolve with ecological processes', Environmental Earth Sciences, vol. 73, no. 3, pp 1067-1082.

Department of Environmental Regulation 2017, Risk Assessments, Guidance statement, Government of Western Australia, Perth.

Department of Transport and Main Roads 2015, 'Chapter 2: general design requirements', Road Drainage Manual, Queensland Government, Brisbane.

Department of Mines and Petroleum \& Environmental Protection Authority 2015, Guidelines for Preparing Mine Closure Plans, Department of Mines and Petroleum, Perth.

Fourie, AB \& Tibbet, M 2007, 'Post-mining landforms - engineering a biological system', in AB Fourie, M Tibbett \& J Wiertz (eds), Proceedings of the Second International Seminar on Mine Closure, Australian Centre for Geomechanics, Perth, pp. 3-12.

International Council on Mining and Metals 2019, Integrated Mine Closure - Good Practice Guide, 2nd edn, London, https://guidance.miningwithprinciples.com/integrated-mine-closure-good-practice-guide/

McLuckie, D, Thomson, R, Drynan, L and Toniato, A 2016 'Risk-based design', in J Ball, M Babister, R Nathan, W Weeks, E Weinmann, M Retallick \& I Testoni (eds), Australian Rainfall and Runoff-A Guide to Flood Estimation, Book1, Commonwealth of Australia, Canberra.

Nathan, R \& Weinmann, E 2016, 'Estimation of very rare to extreme rainfalls', in J Ball, M Babister, R Nathan, W Weeks, E Weinmann, M Retallick \& I Testoni (eds), Australian Rainfall and Runoff - A Guide to Flood Estimation, Book 8, Commonwealth of Australia, Canberra.

Smedley, E, Mackenzie, S \& Gregory, S 2016, 'Surface water assessments-critical for effective landform design', in AB Fourie \& $\mathrm{M}$ Tibbett (eds), Proceedings of the 11th International Conference on Mine Closure, Australian Centre for Geomechanics, Perth, pp. 481-494

World Meteorological Organization 1986, 'Manual for estimation of probable maximum precipitation', 2nd edn, Operational Hydrology Report No. 1, World Meteorological Organization - No. 332, Geneva. 